M. TKADLEČKOVÁ*\#, K. MICHALEK*, K. GRYC*, L. SOCHA*, P. JONŠTA**,

M. SATERNUS***, J. PIEPRZYCA***, T. MERDER***

\title{
RESEARCH AND DEVELOPMENT OF THE SOLIDIFICATION OF SLAB INGOTS FROM SPECIAL TOOL STEELS
}

\begin{abstract}
The paper describes the research and development of casting and solidification of slab ingots from special tool steels by means of numerical modelling using the finite element method. The pre-processing, processing and post-processing phases of numerical modelling are outlined. Also, problems with determining the thermophysical properties of materials and heat transfer between the individual parts of the casting system are discussed. Based on the type of grade of tool steel, the risk of final porosity is predicted. The results allowed to improve the production technology of slab ingots, and also to verify the ratio, the chamfer and the external/ internal shape of the wall of the new designed slab ingots.

Keywords: tool steel, steelmaking, slab ingot, numerical modelling, porosity
\end{abstract}

\section{Introduction}

Increasing the quality of steel products relates to the elimination of defects in steel semi-finished products together with the development of primary production technology, especially casting conditions [1,2], heat treatment, and also with the improvement of subsequent forming of metal materials [3]. Numerical modelling methods [4-8] are among others used to monitor and optimize the production steps from casting to forming processes.

In this study, numerical modelling using the finite element method was applied for research and development of casting and solidification of slab ingots weighing $40 \mathrm{Mg}$ from special tool steels. These ingots are used for the production of special machine components for demanding applications (forged thick steel plates, blocks, pulleys, rods, etc.). These forgings must have very high qualities - free of shrinkage, porosity, segregation or cracks. Due to the numerical modelling, the behaviour of hot metal during mould filling, final porosity, macrosegregation, or the risk of cracks, depending on the boundary conditions, can be predicted. The obtained results allowed to improve the production technology of slab ingots: to choose the best casting temperature, to optimize the regime of mould filling, and also to verify the ratio, the chamfer and the external/internal shape of the wall of the new designed slab ingots to minimize internal defects [9]. The prerequisite of the relevant numerical modelling results is the correct setting of the numerical model.

Obviously, the definition of the numerical model bases on three key stages. In the first stage, it is necessary to create the geometry of the casting system and to generate a computational mesh of the finite elements. In the second phase, the definition of calculation parameters has to be formulated. Determination of some boundary, operating and initial conditions is usually not relatively difficult. The quality of the numerical simulation results of volume defects in ingots is mainly determined by the quality of the thermodynamic and stress properties of the steel and mould material, respectively by the applied conditions of heat transfer among the individual parts of the casting system and by the definition method of the heat losses. Therefore, the problem with determination of the thermophysical properties of materials and of the heat transfer between the individual parts of the casting system is also outlined in this paper.

\section{Thermophysical properties}

In the case of simulating the casting and solidification processes of steel, the following thermodynamic properties depending on the temperature, are needed to know:

- Density,

- $\quad$ enthalpy / heat capacity,

- conductivity,

- viscosity.

Although the methods used for determining the material properties have made a huge advance, it is still very complicated to analyse the values in the area of high temperature, especially concerning the solidus and liquidus temperatures. Also, the

\footnotetext{
VŠB-TECHNICAL UNIVERSITY OF OSTRAVA, FACULTY OF METALLURGY AND MATERIALS ENGINEERING, DEPARTMENT OF METALLURGY AND FOUNDRY, AND REGIONAL MATERIALS SCIENCE AND TECHNOLOGY CENTRE, CZECH REPUBLIC

** VÍTKOVICE HEAVY MACHINERY A.S., OSTRAVA, CZECH REPUBLIC

*** SILESIAN UNIVERSITY OF TECHNOLOGY, INSTITUE OF METALS TECHNOLOGY, KATOWICE, POLAND

\# Corresponding author: marketa.tkadleckova@vsb.cz
} 
identification of these temperatures of phase transformation is still a challenge. Even more complicated it is the case of stress properties specification, which is necessary for predicting the risk of cracks and hot tears. Usually the constant stress values from the forming structure of steel is known, but not from the casting state depending on temperature. In that case the following solution can be applied:

- experimental methods,

- empirical equations,

- Neumann-Kopp rule,

- thermodynamic database,

- values from the literature.

The above mentioned methods are only a few of the experimental methods used for determination of phase transformation temperatures (especially solidus and liquidus), the real steel grades and heat capacity, in thermal analysis. Generally, these methods are based on the detection of the temperature or a dimensional change induced by a heat-tinted process. The most commonly used methods may include:

- direct thermal analysis based on direct measurement of the sample temperature during its continuous linear heating/ cooling, the result is a heating/cooling curve,

- differential thermal analysis (DTA) and/or differential scanning calorimetry (DSC) - the principle of these methods is measurement of the temperature difference (heat-flow difference) between the measured sample and the reference; the result is a DTA curve (or DSC curve) expressing the dependence of the temperature difference between the measured sample and the reference.

Apart from the above-mentioned dynamic methods of thermal analysis, it is also possible to obtain the temperatures of the solidus and liquidus of steel using the broadly known and used empirical equations [10].

The Neumann-Kopp rule is one of the simplest calculations for obtaining heat capacities and their temperature dependences $[11,12]$. When using the Neumann-Kopp rule it is necessary to consider not only the content of individual elements but also the phase, in which the elements are and whether elements form compounds with other elements.

Another way to determine the thermophysical properties of steel is by means of calculation using Fe-C Pseudobinary Phase Diagrams [13]. In the algorithms, the Fe-C pseudobinary phase diagram, which is similar to the $\mathrm{Fe}-\mathrm{C}$ phase diagram but is influenced by the contents of steel alloying elements other than carbon, has been introduced as the basis for solving the phase fractions of steel as functions of temperature.

There is also some software that can calculate the mentioned thermophysical properties when inputting the steel composition, such as ThermoCalc, Dictra, Pandat, IDS, or CompuTherm [14]. Based on the definition of the chemical composition of the steel, the thermodynamic database CompuTherm allows the user to calculate thermodynamic parameters for any new material, or to follow the changes of the thermo-physical data relating to changes in chemical composition [15]. The CompuTherm thermodynamic database was only used for calculation of the thermophysical properties of three special tool steels of the numerical model of casting and solidification of slab ingots. Also, the thermophysical properties of the mould and other parts of the casting system made from cast iron were calculated using the CompuTherm database. Thermal analysis was also used to be sure of the obtained thermophysical values. For the purpose of the paper, the steel grades are indicated as grade A, $\mathrm{B}, \mathrm{C}$. Table 1 shows the content of the main elements, whereas Table 2 presents the obtained temperatures of the liquidus $\left(T_{L}\right)$ and solidus $\left(T_{S}\right)$ steels of $\mathrm{A}, \mathrm{B}$ and $\mathrm{C}$. The approximate calculated thermophysical properties of steels depending on temperature, such as thermal conductivity and enthalpy, are given in Table 3.

TABLE 1

Composition of steel grades in wt. \%

\begin{tabular}{|c|c|c|c|c|c|c|}
\hline \hline Steel grade & $\mathbf{C}$ & $\mathbf{M n}$ & $\mathbf{S i}$ & $\mathbf{C r}$ & $\mathbf{M o}$ & $\mathbf{V}$ \\
\hline $\mathbf{A}$ & 0.37 & 0.37 & 0.90 & 4.99 & 1.20 & 0.43 \\
\hline $\mathbf{B}$ & 0.39 & 0.33 & 0.94 & 5.05 & 1.28 & 0.93 \\
\hline $\mathbf{C}$ & 1.52 & 0.40 & 0.35 & 12.00 & 0.85 & 0.85 \\
\hline
\end{tabular}

TABLE 2

Liquidus and solidus temperatures of the steels in $\mathrm{K}$, calculated using an integrated CompuTherm database

\begin{tabular}{|c|c|c|}
\hline \hline Steel grade & $\boldsymbol{T}_{\boldsymbol{S}}$ & $\boldsymbol{T}_{\boldsymbol{L}}$ \\
\hline $\mathbf{A}$ & 1669 & 1751 \\
\hline B & 1622 & 1746 \\
\hline C & 1497 & 1661 \\
\hline
\end{tabular}

TABLE 3

Thermophysical properties of tested tool steels as a function of temperature

\begin{tabular}{|c|c|c|c|c|c|c|}
\hline \hline \multirow{2}{*}{$\begin{array}{c}\text { Temperature } \\
\text { K }\end{array}$} & \multicolumn{3}{|c|}{$\begin{array}{c}\text { Thermal Conductivity } \\
\mathbf{W} \cdot \mathbf{m}^{\mathbf{1}} \cdot \mathbf{K}^{\mathbf{- 1}}\end{array}$} & \multicolumn{3}{|c|}{$\begin{array}{c}\text { Enthalpy } \\
\mathbf{k J}^{\prime} \cdot \mathbf{k g}^{-1}\end{array}$} \\
\cline { 2 - 7 } & $\mathbf{A}$ & $\mathbf{B}$ & $\mathbf{C}$ & $\mathbf{A}$ & $\mathbf{B}$ & $\mathbf{C}$ \\
\hline 301 & 59 & 58 & 55 & 0 & 0 & 0 \\
\hline 467 & 42 & 42 & 38 & 84 & 82 & 93 \\
\hline 782 & 34 & 34 & 30 & 282 & 287 & 304 \\
\hline 1091 & 32 & 31 & 25 & 561 & 572 & 624 \\
\hline 1138 & 26 & 26 & 22 & 630 & 627 & 653 \\
\hline 1676 & 31 & 34 & 26 & 995 & 1054 & 1280 \\
\hline 1714 & 35 & 34 & 27 & 1118 & 1129 & 1320 \\
\hline 1751 & 29 & 29 & 28 & 1277 & 1271 & 1345 \\
\hline 2273 & 37 & 36 & 33 & 1708 & 1672 & 1774 \\
\hline
\end{tabular}

\section{Heat Transfer}

Definition of the heat transfer coefficients among the individual components of the casting system is not simple. The heat transfer coefficients are defined individually for each of the components contact interfaces, such as, for example, the heat transfer coefficient between the ingot and ingot mould, between the ingot and the insulation, etc. 
The equation (1) shows the three possible contributions to the "Heat" boundary condition [16]:

$$
Q=F l u x+h\left(T-T_{a}\right)+\sigma \varepsilon\left(T^{4}-T_{a}^{4}\right)
$$

where the first term corresponds to a specified flux (Flux). It can be used if a given heat flux was measured for instance. The second term corresponds to Convective cooling. This is the most common definition of the cooling of an external face. It is defined by a heat transfer coefficient $(h)$ and difference in ambiance $\left(T_{a}\right)$ and external temperature $(T)$. The third term is used at high temperature, when radiation becomes important. In this case, the transfer is proportional to the Stefan-Bolzmann constant $(\sigma)$, emissivity $(\varepsilon)$ and the difference of the fourth power of the surface $(T)$ and ambiance $\left(T_{a}\right)$ temperatures. The constant values in the range from 100 (e.g. between the hot top and the insulation) to $1000 \mathrm{~W} \cdot \mathrm{m}^{-2} \cdot \mathrm{K}^{-1}$ (between the mould and the ingot) are usually given in literature. However, previous research, has found that the heat transfer coefficients should be set depending on the time or temperature.

\section{Boundary Conditions}

The knowledge and optimization of the existing casting parameters/boundary conditions, such as casting speed, casting temperature of steel or the H/D ingot ratio, are the main precondition for minimization of steel ingot defects, especially of porosity, macrosegregation and cracks. As it is evidenced by the results of the model and experimental studies performed e.g. by the authors [16,17], the size of the central defect is strongly dependent on the shape of the ingot and the hot top.

Therefore, in the previous work [18], attention was devoted to optimizing the shape of the slab ingot. A complex change of the internal and external walls of the mould and hot top was designed. Also, the boundary conditions, such as casting speed (resp. the character of the filling regime) and casting temperature, significantly influence the final temperature filed after casting as a starting point for solidification. Table 4 presents the boundary conditions of the casting of studied steel grades into slab ingots.

\section{Computational conditions}

For calculation of filling and solidification only one type of computational mesh of the finite elements was used. The whole process was calculated in one step. The final surface and volume computational mesh of finite tetra elements used in this study are shown in Fig. 1. The slab ingots are distinguished by the characteristic aspect ratio A / B, therefore in Fig. 1 can be seen the cut section in two directions. The cut section in the thickness of the slab ingot allows to see the two inlets for casting steel melt. The average size of the tetra elements was approximately $30 \mathrm{~mm}$. The total numbers of tetra elements was $1,577,115$.
TABLE 4

Boundary conditions of the steel casting process

\begin{tabular}{|c|c|c|c|}
\hline \hline Steel Grade & Parameter & Unit & Value \\
\cline { 1 - 2 } $\mathbf{A}$ & & & $T_{L}+60$ \\
\cline { 1 - 2 } $\mathbf{B}$ & Casting Temperature & $\mathrm{K}$ & $T_{L}+70$ \\
\cline { 1 - 2 } $\mathbf{C}$ & & $\mathrm{s}$ & $T_{L}+80$ \\
\hline $\mathbf{A}, \mathbf{B}, \mathbf{C}$ & Total Filling Time & $\mathrm{K}$ & 2960 \\
\hline $\mathbf{A}, \mathbf{B}, \mathbf{C}$ & Ambient Temperature & - & 0.85 \\
\hline $\mathbf{A}, \mathbf{B}, \mathbf{C}$ & Emissivity & $\mathrm{K}$ & 323 \\
\hline $\mathbf{A}, \mathbf{B}, \mathbf{C}$ & Temperature of mould preheating & $\mathrm{m} \cdot \mathrm{s}^{-2}$ & 9.8 \\
\hline $\mathbf{A}, \mathbf{B}, \mathbf{C}$ & Gravity acceleration & $\mathrm{m}$ & \\
\hline
\end{tabular}
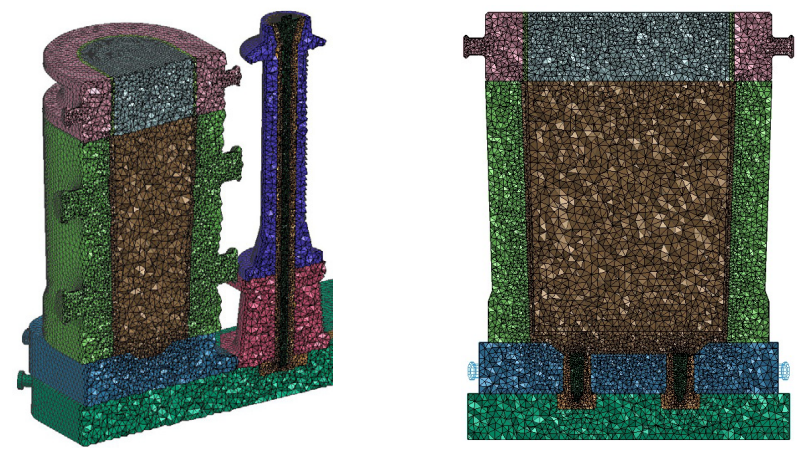

Fig. 1. The final surface and volume computational mesh of finite elements of the slab ingot

For calculation of the porosity and shrinkage cavity, the equations have to be activated using the so-called simulation or run parameters. These parameters activate calculation of the Fourier heat conduction equation, including latent heat release during solidification, a fluid flow calculation solved using the Navier-Stokes equation, or calculation of redistribution of the element in the case of macrosegregation calculation.

Based on the simulation parameters, it is possible to specify also the maximum time step size, which will be used during the filling stage only. Also, stop criteria and convergence conditions can be defined. The example of stop criteria and other parameters used in this study are presented in Table 5 .

TABLE 5

The example of assumed simulation parameters

\begin{tabular}{|l|c|c|}
\hline \multicolumn{1}{|c|}{ Parameter } & Abbreviation & Value \\
\hline $\begin{array}{l}\text { Stop criterion: Maximum number } \\
\text { of time steps }\end{array}$ & NSTEP & 5000 \\
\hline Stop criterion: Final temperature & TSTOP & $1,660 \mathrm{~K}$ \\
\hline $\begin{array}{l}\text { Frequency of temperature results } \\
\text { storage }\end{array}$ & TFREQ & 50 \\
\hline Porosity - Critical macro-porosity & MACROFS & 0.7 \\
\hline Porosity - Feed Length & FEEDLEN & $0.02 \mathrm{~m}$ \\
\hline
\end{tabular}

\section{Discussion of the achieved results}

The numerical modelling results predicted the character of the steel flow during mould filling, the velocity of the steel flow 
(which is important for determining of the cover powder entrainment inside the steel during the casting), the final temperature field after filling, the character of the solidification using a fraction solid, and finally the total solidification time and the internal porosity depending on the type of cast steel grade.

\subsection{Character of the steel flow}

Bottom filling via two inlets was calculated. It is evident from Fig. 2 (where the character of the steel flow during the mould filling is shown using velocity vectors) that during the casting, it can be observed the connection of streams for all modelled cases. The connection of streams is possible to explain due to natural convection in this way: near the wall inside of the mould the steel is cooling and, because of the higher density, the steel sinks to the bottom of the mould. There, the stream of cooler steel turns in the direction of the inlets where the new steel is supplied. The cooler steel is partially mixed with the "new" warmer steel; nevertheless, the main streams are due to the strong influence of the cooler streams pressing together. In the end, the streams are connected.

Near the surface, the risk of cover powder entrainment back into the steel melt can be observed.

\subsection{Porosity}

The porosity is induced by two mechanisms: solidification shrinkage and gas segregation. The porosity was numerically solved based on the model developed by Pequet, Gremaud and Rappaz. Further details are presented in $[19,20]$.
The porosity also relates to changes in the temperature field and character of solidification. Fig. 3 shows the character of the fraction solid during the final stages of solidification, whereas Fig. 4 compares the final porosity and size of the shrinkages for three modelled special tool steel grades. The porosity is shown in numerical results by whole elements (computational cells) with a certain non-filled percentage of metal volume. It means that this concerns not only porosity. That is why porosity may appear in simulations larger than it will be in reality. Moreover, the microporosity (share of the volume of the calculated cell not filled with metal), varying up to $2 \%$, may be fully eliminated by the following forging. In comparison with the original mould design published in [18], from Fig. 4 it can be seen that the final porosity of steel grades A nd B is much smaller. The total volume of porosity of steel grade A was $45 \mathrm{~cm}^{3}$ and for steel grade B only $12 \mathrm{~cm}^{3}$. On the other hand, in the case of steel grade $C$, the new mould design did not bring the expected efficiency and the total volume of the porosity was $870 \mathrm{~cm}^{3}$. This huge porosity was caused by the wide two-phase zone between the liquidus and solidus temperatures of this steel grade. The most dangerous area for the origination of porosity can be found in the middle of the height of the ingot, where the filling of the hot metal from the hot top is much more complicated.

\section{Conclusion}

The paper was devoted to verification of the production of a slab ingot weighing $40 \mathrm{Mg}$ from special tool steels using numerical modelling with the finite element method.

Attention was focused on predicting final porosity depending on the new mould design and depending on the type of the

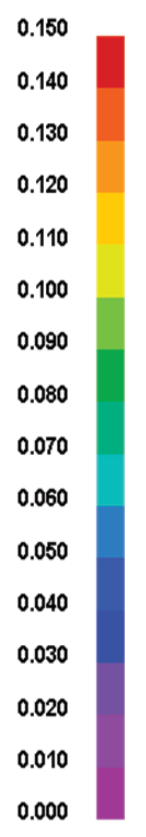

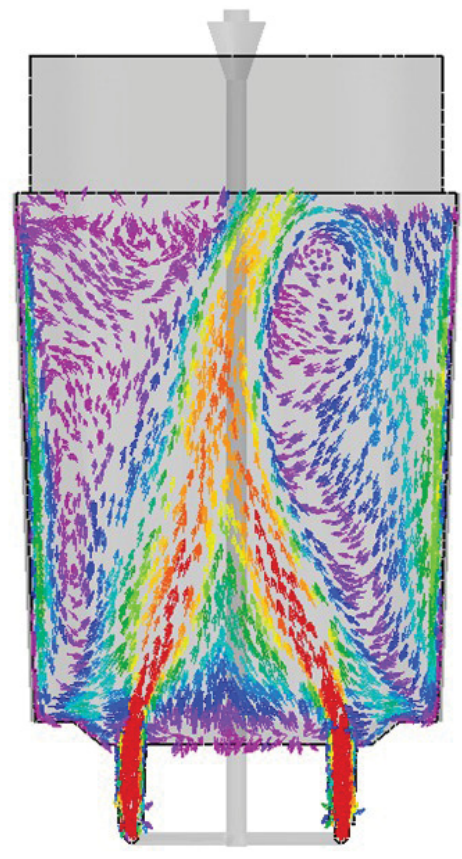

Steel Grade B

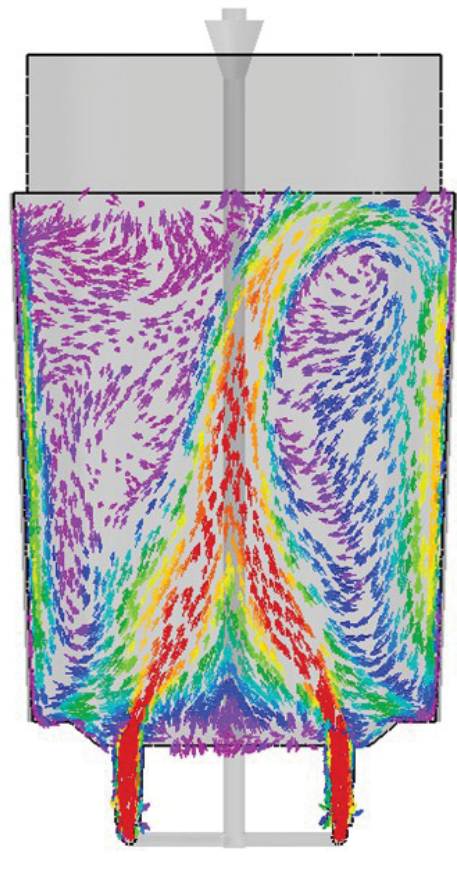

Steel Grade C

Fig. 2. The character of the steel flow during bottom filling of the slab mould using velocity vectors in $\mathrm{m}^{*} \mathrm{~s}^{-1}$ for three simulated steel grades 

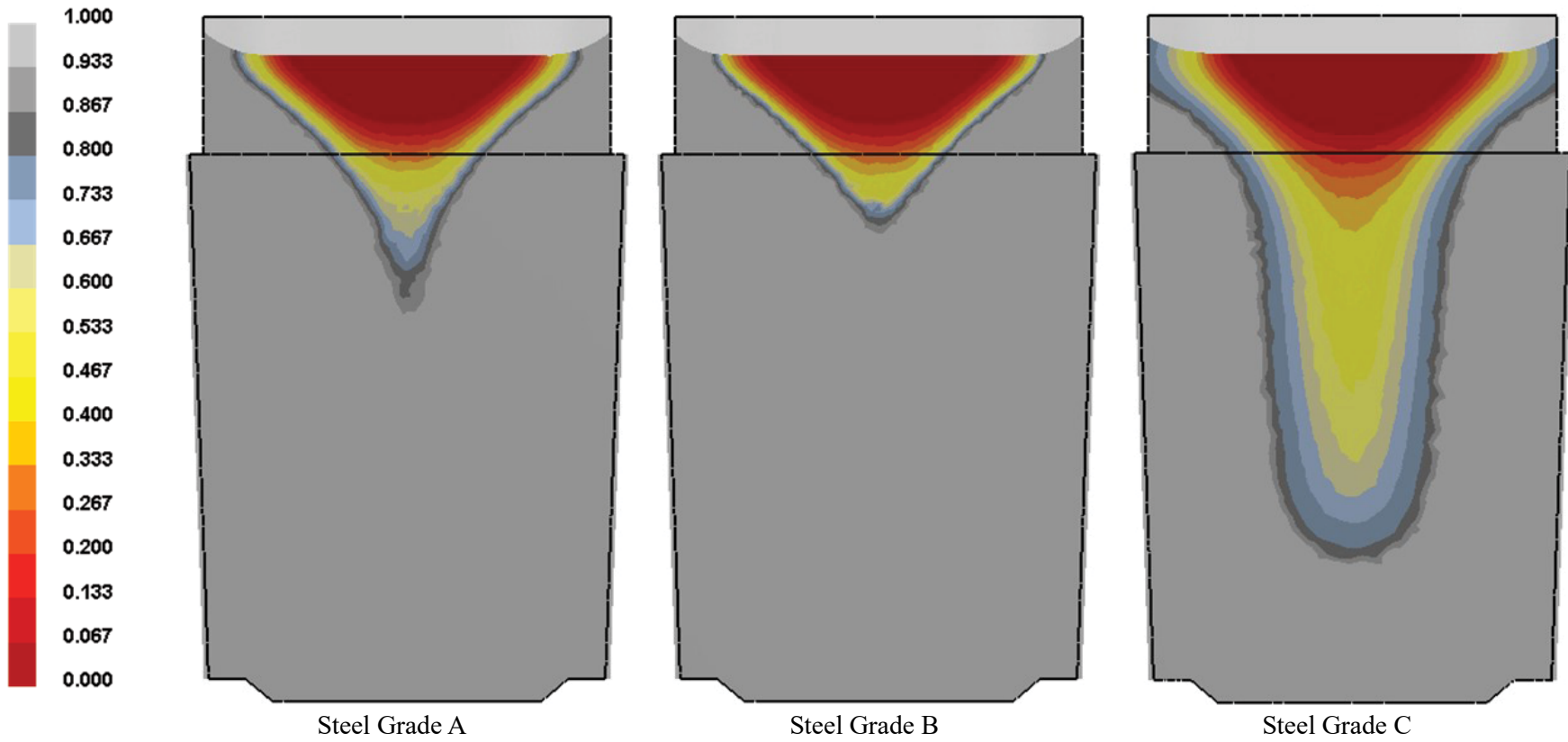

Fig. 3. The character of the solid fraction during the final stages of solidification

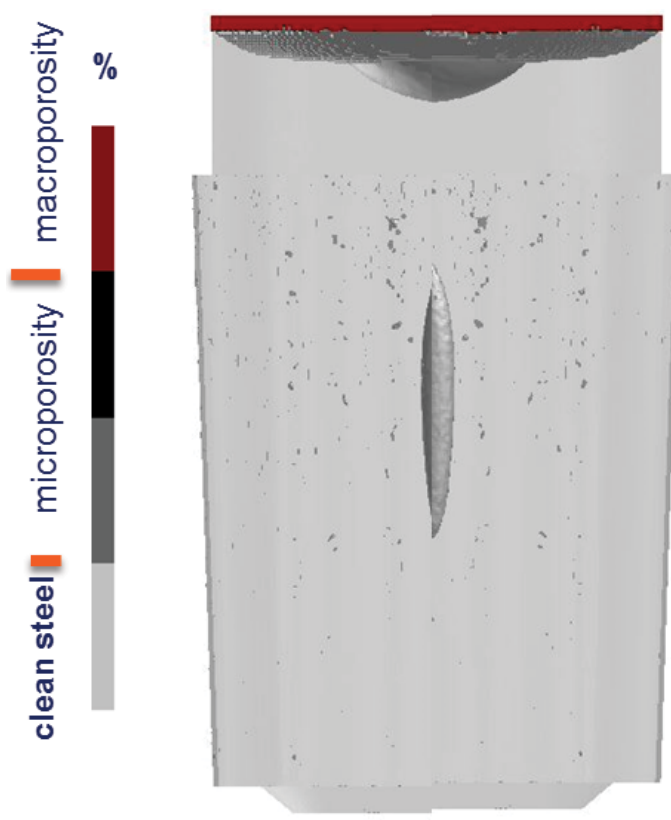

Steel Grade A

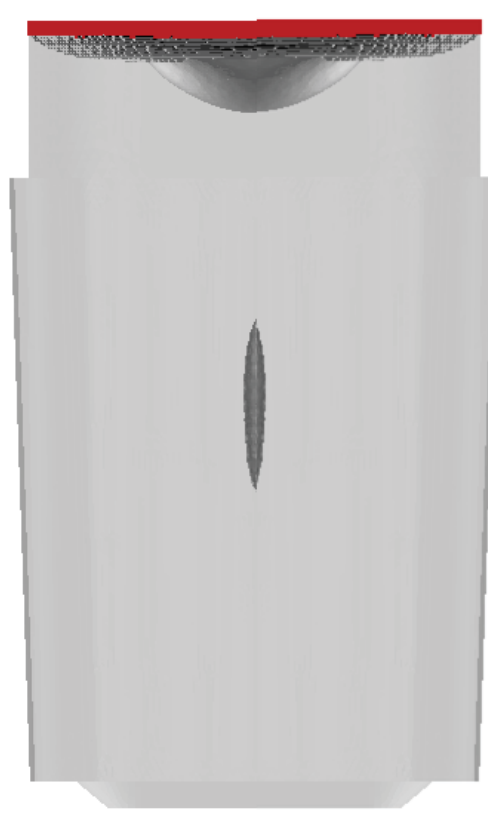

Steel Grade B

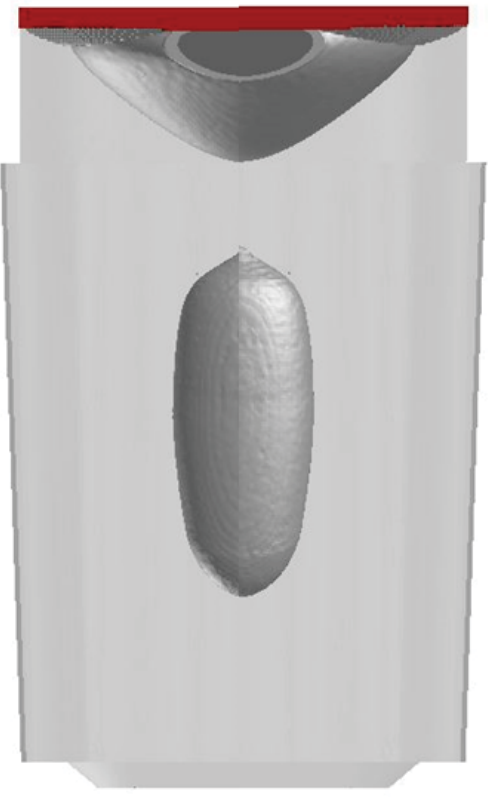

Steel Grade C

Fig. 4. Comparison of final porosity for three special tool steel grades cast into slab ingots

cast tool steel grades. These steel grades were chosen by the high content of their alloying elements, like as chromium, vanadium and molybdenum.

Using numerical modelling, it was found that:

- the quality of the numerical modelling related to the accuracy of the thermophysical properties of the calculated steel grades;

- the thermophysical properties can be established by experimental thermal analysis, by empirical equations, by thermodynamic rules (such as, for example, the Neumann-Kopp rule for calculating heat capacity), by thermodynamical calculation using software or equilibrium diagrams;
- definition of the heat transfer coefficients between individual components of the casting system is not simple. The heat transfer coefficients are very dependent on the quality of the surface contact between the ingot and mould or parts of the casting system;

- when compared with the classical polygonal ingots or with the original shape of the slab ingot, in the new design of a slab ingot it can be also expected the typical macrostructure porosity character;

- $\quad$ the size and position of porosity for steel grades A and B are more appropriately situated for forgings such as thick steel plates; a different situation was found in the case of 
steel grade $\mathrm{C}$ where the porosity achieved a huge volume of about $870 \mathrm{~cm}^{3}$. In this case, it would be useful to optimize / change the boundary conditions of the casting or to verify the additional mould designs.

Based on these results, the next research will be focused on the verification of the volume defects of this slab ingot under different boundary conditions; especially, the A / B ratio, the chamfer and the profile of the mould will be changed. Also, the macrosegregation character and the risk of cracking will be evaluated.

\section{Acknowledgements}

This paper was created with the financial support of TA CR under Project No. TA04010035, in Project No. LO1203 "Regional Materials Science and Technology Centre - Feasibility Programme" funded by the Ministry of Education, Youth and Sports of the Czech Republic, and from the support of "Student Grant Competition" projects, No.SP2017/57 and SP2017/58. This work was also supported by Polish Ministry for Science and Higher Education under internal grant BK264/RM2/2016 for Institute of Metals Technology, Silesian University of Technology, Poland.

\section{REFERENCES}

[1] M. Kearney, M. Crabbe, J. Talamantes-Silva, Ironmaking and Steelmaking 34 (5), 380-383 (2007).

[2] S. Baoguang, K. Xiuhong, L. Dianzhong, J. Mater. Process. Tech. 210 (4), 703-711 (2010).

[3] H. Kakimoto, T. Arikawa, Z. Takahashi, T. Tanaka, Z. Imaida, J. Mater. Process. Tech. 210, 415-422 (2010).
[4] O. Bogdan, Industrial Soft, Montreal, Canada (2010), http:// castingsnet.com/AISI4340-casting-report.pdf.

[5] W. Song, J.M. Zhang, Y. Liu, S.X. Wang, B. Wang, Ironmak. Steelmak 42 (9), 656-663 (2015).

[6] P. Lan, J. Q. Zhang, Ironmak. Steelmak. 41 (8), 598-606 (2014).

[7] K. Marx, S. Rödl, S. Schramhauser, M. Seemann, La Metallurgia Italiana 11-12, 11-19 (2014).

[8] T. Merder, M. Saternus, M. Warzecha, P. Warzecha, Metalurgija 53 (3), 323-326 (2014).

[9] M. Balcar, L. Sochor, R. Železný, P. Fila, L. Martínek, L. Kraus, D. Kešner, J. Bažan. In $16^{\text {th }}$ Intern. Conf. on Metall. and Mater. METAL 2007. Hradec n. Moravicí, EU. (in Czech). http://konsys-t. tanger.cz/files/proceedings/metal 07/Lists/Papers/169.pdf.

[10] K. Gryc, B. Smetana, M. Žaludová, K. Michalek, P. Klus, M. Tkadlečková, L. Socha, J. Dobrovská, P. Machovčák, L. Válek, R. Pachlopnik, B. Chmiel, Mater. Tehnol. 47(5), 569-575 (2013).

[11] M. Žaludová, B. Smetana, S. Zlá, J. Dobrovská, S. Rosypalová, A. Kalup, K. Michalek, In $23^{\text {th }}$ Anniv. Intern. Conf. on Metall. and Mater. METAL 2014. Brno, EU, (2014). ISBN 978-80-87294-54-3.

[12] J. Leitner, P. Voňka, D. Sedmidubský, P. Svoboda, Thermochimica Acta 497, 7-13 (2010).

[13] Y. Xie, J. Yang, Steel. Res. 86 (7), 766-774 (2015).

[14] S. Hahn, T. Schaden, BHM 159 (11), 438-446 (2014).

[15] ProCAST 2016.0 User's Guide.

[16] A. Kermanpur, M. Eskandar, H. Purmohamad, M.A. Soltan, B. Shater, Materials and Design 31 (3), 1096-1104 (2010).

[17] V.A. Shamrei, S.I. Zhul'ev, Metallurgist 51 (11), 617-623 (2007).

[18] M. Tkadlečková, K. Michalek, K. Gryc, L. Socha, P. Machovčák, Metalurgija 55 (3), 395-398 (2016).

[19] Ch. Pequet, M. Gremaud, M. Rappaz, Met. Mater. Trans. 33A, 2095-2106 (2002).

[20] G. Couturier, M. Rappaz, Model. and Simul. in Mater. Scien. and Engin. 14, 253-271 (2006). 